\title{
PERANCANGAN SISTEM INFORMASI REKAM MEDIS PADA PUSKESMAS JOMIN BERBASIS WEB
}

\author{
${ }^{1}$ Agung Prasetyo, ${ }^{2}$ Mohammad Syamsul Azis \\ agungprivate1@gmail.com, azisnice3@gmail.com
}

\begin{abstract}
Abstrak
Sistem informasi rekam medis merupakan sistem untuk mengelola data pasien dan dokumen antara lain identitas pasien, hasil pemeriksaan, pembayaran dan pelayanan lain yang telah diberikan kepada pasien. Adapun sistem rekam medis dan pembuatan laporan pada Puskesmas tersebut pengolahannya masih manual dan masih menggunakan media pembukuan dan memakan banyak tempat. Oleh karena itu pelayanan pasien di Puskesmas menjadi kurang efektif dan efisien. Dengan menggunakan website sebagai alat bantu dalam pengolahan data dapat mempermudah pengolahan data rekam medis dan membuat laporan dengan cara yang lebih mudah dan efisien dan dapat menghemat tempat yang telah disediakan. Metode yang digunakan dalam membangun aplikasi website ini menggunakan metode waterfall yang dimulai dari analisis, desain, kode, pengujian dan pemeliharaan. Sistem informasi rekam medis berperan penting untuk meningkatkan pelayanan pada Puskesmas Jomin, Sehingga memudahkan Puskesmas dalam mengolah data pasien, data kunjungan, rekam medis pasien dan laporannya.
\end{abstract}

Kata Kunci: Rekam Medis, Rekam Medis Jomin

\begin{abstract}
Medical record information system is a system for managing patient data and documents such as patient identity, examination result, payment and other services that have been given to the patient. The medical record system and reporting on the Puskesmas is still manual processing and still use bookkeeping media and takes up a lot of places. Therefore, patient care in Puskesmas become less effective and efficient. By using the website as a tool in data processing can facilitate the processing of medical record data and create reports in a way that is easier and efficient and can save the place that has been provided. The method used in building this website application using waterfall method that starts from analysis, design, code, testing and maintenance. Medical record information system plays an important role to improve services at Puskesmas Jomin, making it easier for Puskesmas in processing patient data, visit data, patient medical record and report.
\end{abstract}

Keywords: Medical Record, Jomin Medical Record 


\section{PENDAHULUAN}

Rekam medis adalah berkas yang berisi catatan dan dokumen antara lain identitas pasien, hasil pemeriksaan, pengobatan yang telah diberikan, serta tindakan dan pelayanan lain yang telah diberikan kepada pasien. Catatan merupakan tulisan-tulisan yang dibuat oleh dokter atau dokter gigi mengenai tindakan-tindakan yang dilakukan kepada pasien dalam rangka palayanan kesehatan. Rekam medis terdiri dari catatan-catatan data pasien yang dilakukan dalam pelayanan kesehatan. Catatan-catatan tersebut sangat penting untuk pelayanan bagi pasien karena dengan data yang lengkap dapat memberikan informasi dalam menentukan keputusan baikpengobatan, penanganan, tindakan medis dan lainnya. Dokter atau dokter gigi diwajibkan membuat rekam medis sesuai aturan yang berlaku.

Sistem pencatatan rekam medis yang dipakai di Puskesmas Jomin, Kecamatan Kota baru, Kabupaten Karawang selama ini masih memiliki kelemahan. Karena data rekam medis pasien hanya tersimpan secara lokal di tempat dimana pasien tersebut menjalani pemeriksaan dan perawatan medis dan antar tempat tidak memungkinkan pertukaran data secara langsung.

Pasien yang menjalani pemeriksaan dan perawatan medis pada beberapa instansi medis maka pada tiap-tiap instansi medis akan menyimpan data rekam medis yang berbedabeda dan tiap instansi medis tidak mempunyai data riwayat kesehatan pasien sebelum menjalani pemeriksaan kesehatan di instansi medis tersebut. Hal ini membutuhkan proses yang cukup rumit dan waktu yang cukup lama. Karena selain pasien harus mengurus klaim pengajuan asuransi juga harus mengurus berkas-berkas yang dibutuhkan untuk pengajuan klaim dari instansi medis tempat dia menjalani perawatan.

Karena adanya kelemahan yang dimiliki oleh sistem pencatatan rekam medis pasien yang ada saat ini, maka penelitian ini bertujuan untuk mendapatkan alternatif teknologi yang dapat diterapkan di masa yang akan datang untuk pencatatan dan penyampaian data rekam medis.

Maksud dari penelitian ini adalah untuk Merancang website berbasis aplikasi rekam medis pada puskesmas Jomin, Kecamatan Kota baru, Kabupaten Karawang agar mempermudah pasien dalam berobat di sana.

\section{TINJAUAN PUSTAKA}

\section{Pengertian Sistem}

Menurut Davis (2013:16), "Sistem merupakan gabungan dari berbagai elemen yang bekerja sama untuk mencapai suatu target".

Menurut Mulyadi (2016:4), "Sistem adalah suatu jaringan prosedur yang dibuat menurut pola yang terpadu untuk melaksanakan kegiatan pokok perusahaan”.

\section{Pengertian Sistem Informasi}

Menurut Krimaji (2015:14), "informasi adalah data yang telah diorganisasi dan telah memiliki kegunaan dan manfaat". Sedangkan untuk sistem informasi sendiri menurut Krismaji (2015:15), "Sistem informasi adalah sebuah rangkaian prosedur formal dimana data dikelompokkan, diproses, menjadi informasi, dan didistribusikan kepada pemakai".

\section{Pengertian Rekam Medis}

Rekam Medis menurut Purnama dan Renny Afriany N, dalam Jurnal Manajemen Sistem Informasi (2016:147), adalah "Bukti tertulis mengenai proses pelayanan yang diberikan kepada pasien oleh dokter dan tenaga kesehatan lainnya, yang mana dengan adanya bukti tertulis tersebut maka rekam medis yang diberikan dapat dipertanggungjawabkan, dengan tujuan sebagai penunjang tertib administrasi dalam upaya peningkatan pelayanan kesehatan rekam medis".

\section{Pengertian Website}

Menurut Nilasari (2014:11), “Website atau juga sering disebut "situs merupakan kumpulan halaman web yang dijalankan dari satu alamat web domain." 


\section{METODOLOGI PENELITIAN}

\section{Metode Pengembangan Perangkat Lunak}

Menurut Sommerville (2013:30), tahapan utama dari waterfall model langsung mencerminkan aktifitas pengembangan dasar. Terdapat 5 tahapan pada waterfall model, yaitu requirement analysis and definition, system and software design, implementation and unit testing, integration and system testing, dan operation and maintenance.

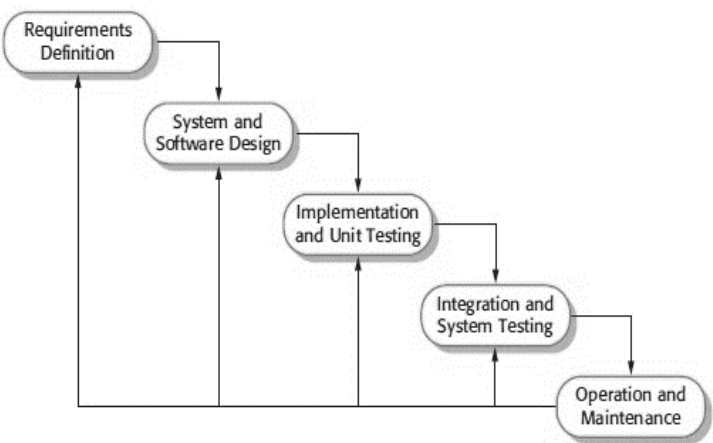

Sumber : (Sommerville, 2011:30)

Gambar 1. Model Waterfall

Berikut adalah penjelasan dari tahapantahapan tersebut :

\section{Requirement Analysis and Definition}

Merupakan tahapan penetapan fitur, kendala dan tujuan sistem melalui konsultasi dengan pengguna sistem. Semua hal tersebut akan ditetapkan secara rinci dan berfungsi sebagai spesifikasi sistem.

\section{System and Software Design}

Dalam tahapan ini akan dibentuk suatu arsitektur sistem berdasarkan persyaratan yang telah ditetapkan. Dan juga mengidentifikasi dan menggambarkan abstraksi dasar sistem perangkat lunak dan hubungan-hubungannya.

\section{Implementation and Unit Testing}

Dalam tahapan ini, hasil dari desain perangkat lunak akan direalisasikan sebagai satu set program atau unit program. Setiap unit akan diuji apakah sudah memenuhi spesifikasinya.

\section{Integration and System Testing}

Dalam tahapan ini, setiap unit program akan diintegrasikan satu sama lain dan diuji sebagai satu sistem yang utuh untuk memastikan sistem sudah memenuhi persyaratan yang ada. Setelah itu sistem akan dikirim ke pengguna sistem.

\section{Operation and Maintenance}

Dalam tahapan ini, sistem diinstal dan mulai digunakan. Selain itu juga memperbaiki error yang tidak ditemukan pada tahap pembuatan. Dalam tahap ini juga dilakukan pengembangan sistem sepertipenambahan fitur dan fungsi baru.

\section{Teknik Pengumpulan Data}

Pengumpulan data yang diperlukan, penulis menggunakan beberapa penelitian yaitu :

1. Observasi

Observasi yaitu dengan melakukan pengamatan langsung terhadapsistem rekam medis pada puskesma Jomin, Kecamatan Kota baru, Kabupaten Karawang. Data yang dikumpulkan dari puskesmas tersebut berupa data rekam medis pasien, fasilitas poliklinik yang tersedia, alir sistem rekam medis, dan kartu pendaftaran.

2. Wawancara

Pada metode ini penulis mengumpulkan data secara tatap muka langsung dengan orang yang diwawancarai. Dalam hal ini penulis mengadakan tanya jawab dengan Neneng Rohayati, S.E. Selaku Ka.Subag Tata Usaha Puskesmas Jomin, bertanya tentang sejarah berdirinya puskesmas dan profil tentang puskesmas tersebut.

3. Studi Pustaka

Melakukan tinjauan pustaka melalui buku tentang bahasa pemrograman website dan laporan yang berhubungan dengan aplikasi rekam medis, seperti Buku Tugas Akhir.

\section{HASIL DAN PEMBAHASAN}

\section{Rancangan Antar Muka}

Perancangan antar muka bertujuan untuk memberikan gambaran tentang aplikasi yang akan dibangun, sehingga akan mudah dalam mengimplementasikan aplikasi. Dan juga memudahkan pembuatan aplikasi yang user friendly. 
Rancangan aplikasi sistem informasi website kami adalah sebagai berikut:

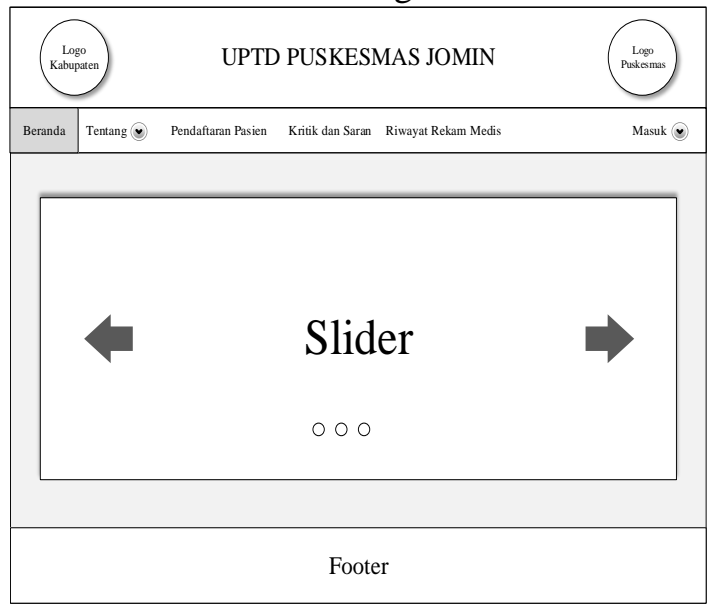

Gambar 1. Rancangan Antar Muka Beranda Pasien

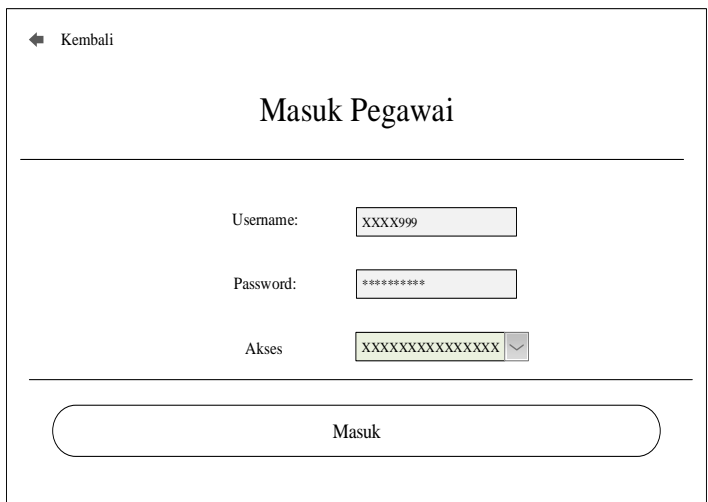

Gambar 2. Rancangan Antar Muka Masuk Pegawai

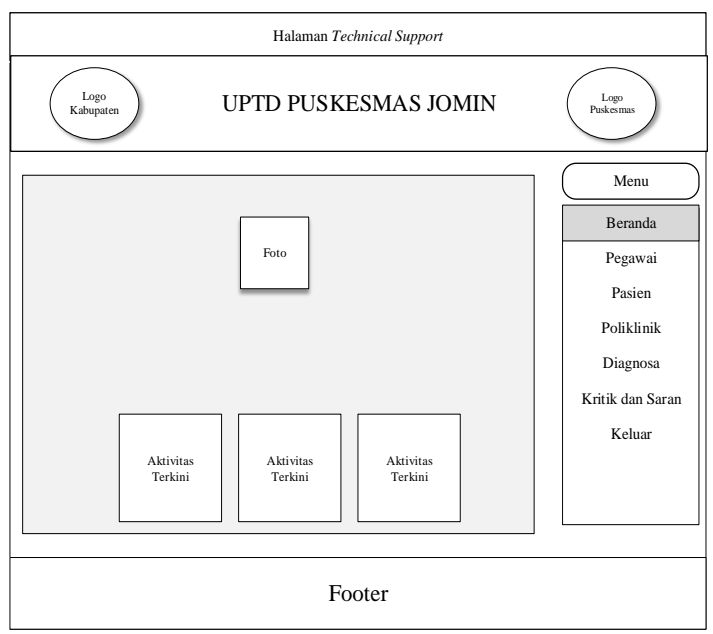

Gambar 3. Rancangan Antar Muka Pegawai Administrasi

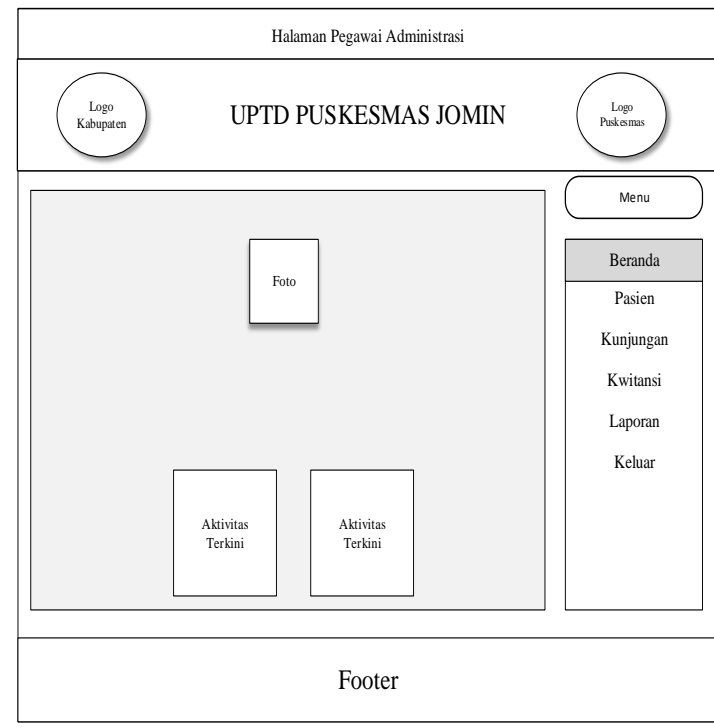

Gambar 4. Rancangan Antar Muka Pegawai Staff Poli

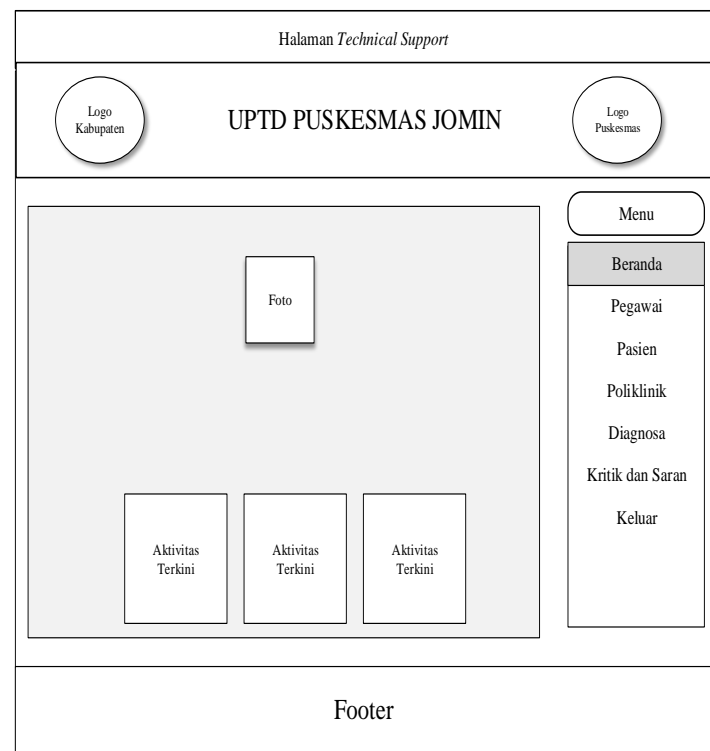

Gambar 5. Rancangan Antar Muka Pegawai Technical Support 


\section{Rancangan Basis Data}

\section{Entity Relationship Diagram}

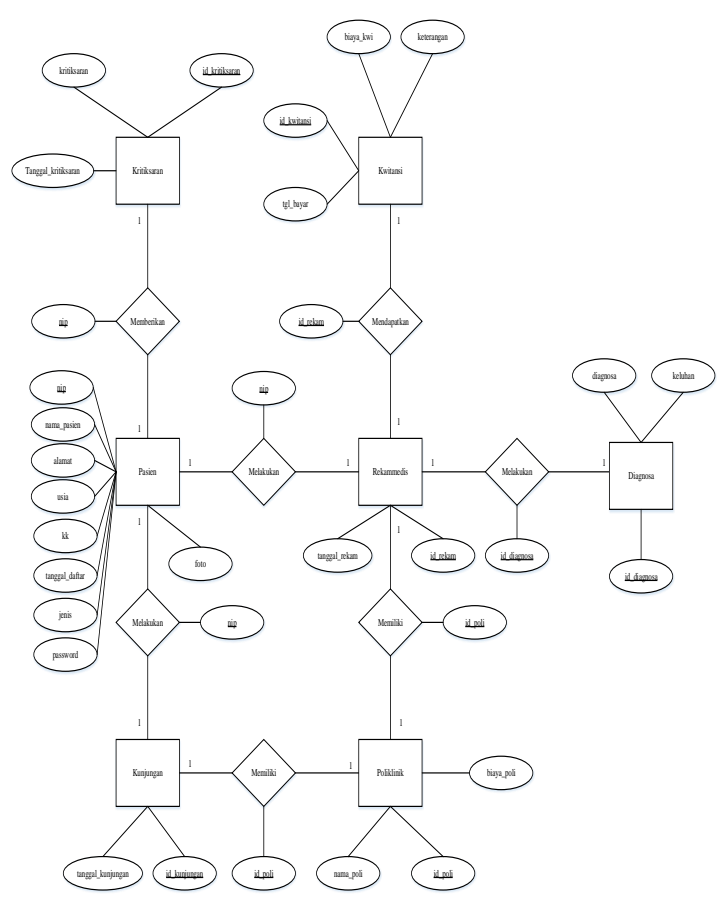

Gambar 6. Entity Relationship Diagram

\section{Logical Relation Structure}

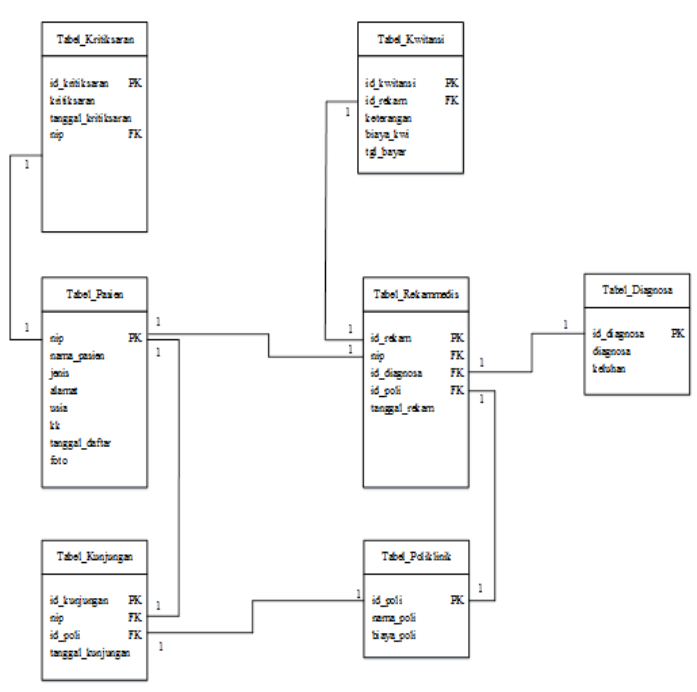

Gambar 7. Logical Relation Structure

\section{Struktur Navigasi}

1. Struktur Navigasi Pasien

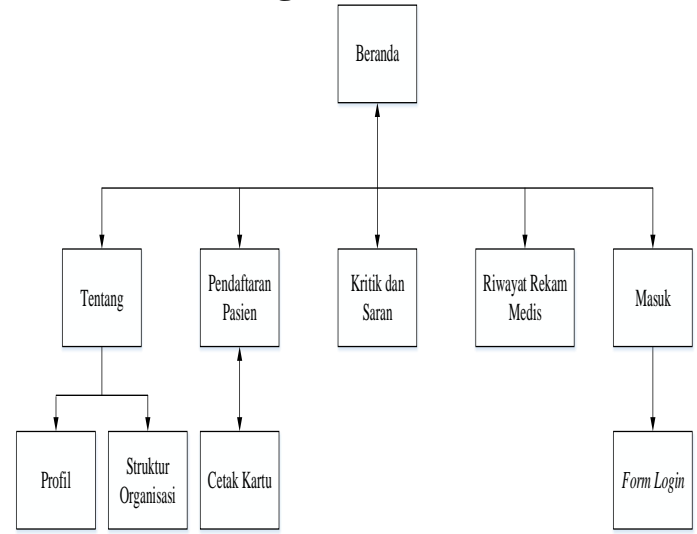

Gambar 8. Struktur Navigasi Pasien

2. Struktur Navigasi Pegawai Administrasi

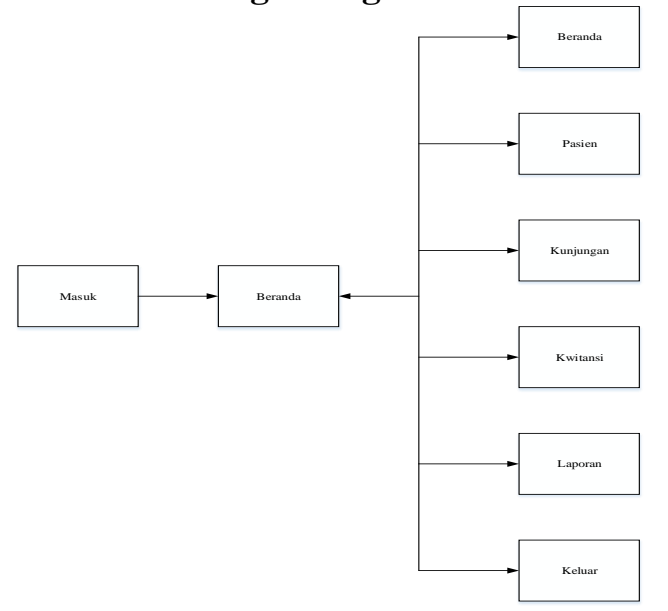

Gambar 9. Struktur Navigasi Pegawai Administrasi

3. Struktur Navigasi Pegawai Staff Poli

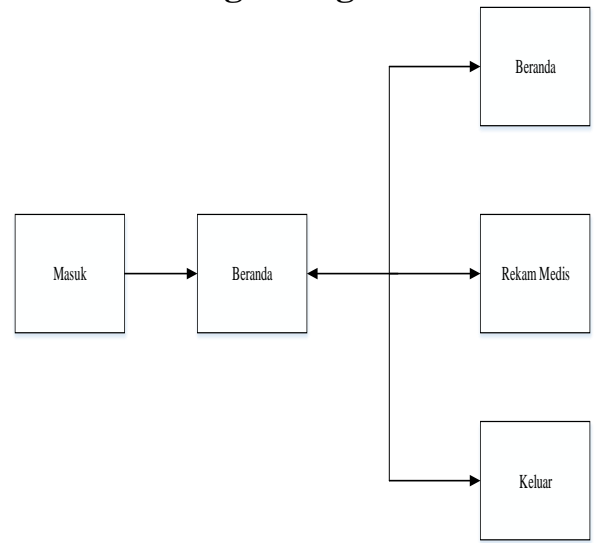

Gambar 10. Struktur Navigasi Pegawai Staff Poli 
4. Struktur Navigasi Pegawai Technical Support

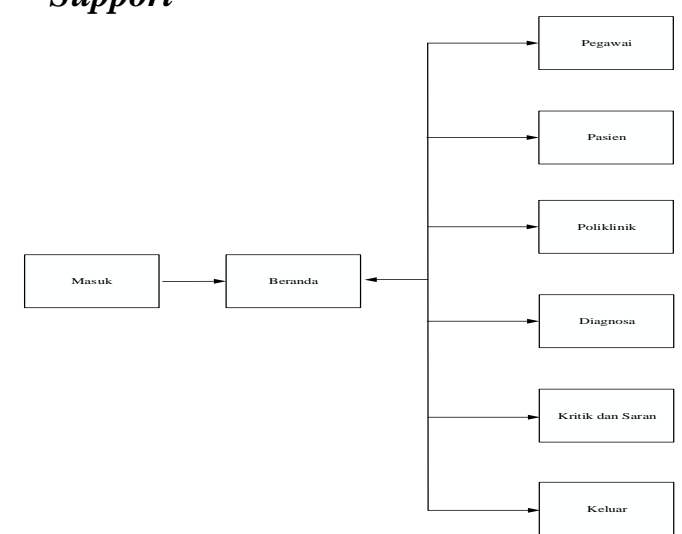

Gambar 11. Struktur Navigasi Pegawai Technical Support

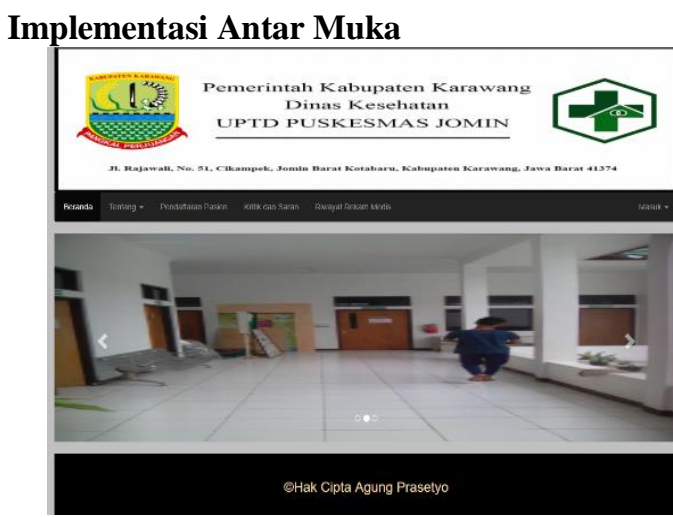

Gambar 12. Halaman Beranda Pasien

Gambar 12 halaman Pasien berisi tampilan slider yang berfungsi untuk menampilkan gambar dari puskesmas yang akan dikunjungi.

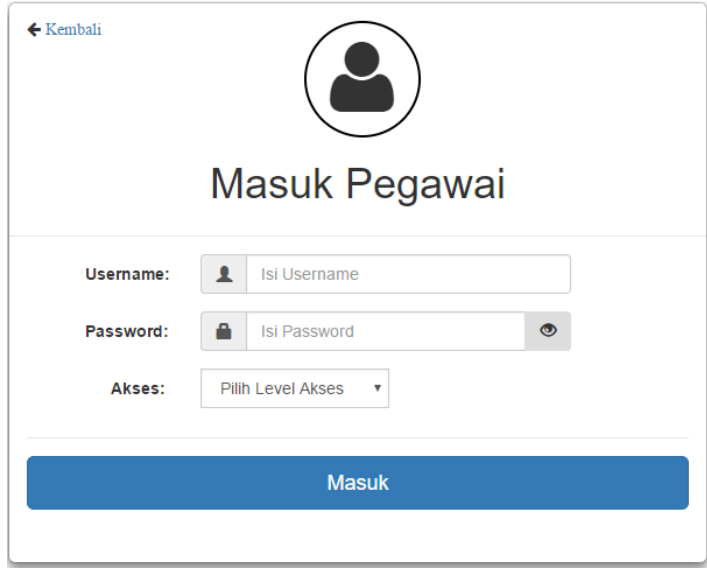

Gambar 13. Halaman Masuk Pegawai
Gambar 13, pegawai harus memilih akses level dahulu sebelum masuk. Akses level terdiri dari 3 level, yaitu untuk pegawai administrasi, Staff Poli dan pegawai tehnical support.

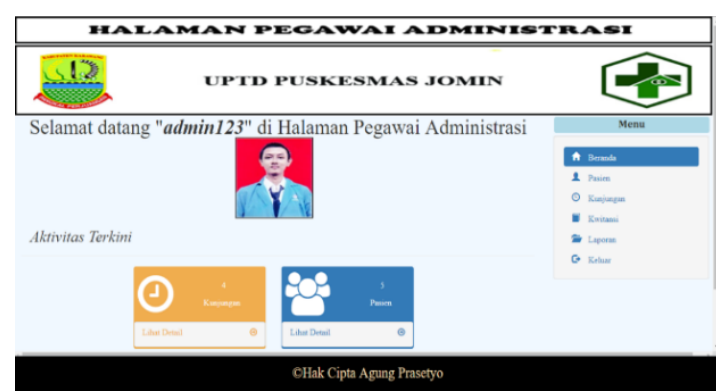

Gambar 14. Halaman Beranda Pegawai Administrasi

Gambar 14, halaman Pegawai Administrasi ini berisikan aktivitas terkini mengenai jumlah kunjungan pasien dan jumlah pasien lalu terdiri dari beberapa menu untuk keperluan administrasi.

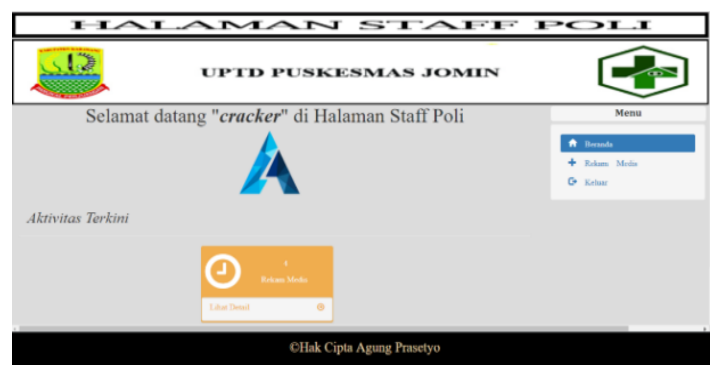

Gambar 16. Halaman Beranda Pegawai Staff Poli

Gambar 16, halaman Pegawai Administrasi ini berisikan aktivitas terkini mengenai aktivitas terkini dari rekam medis dan menu untuk mengelola data rekam medis.

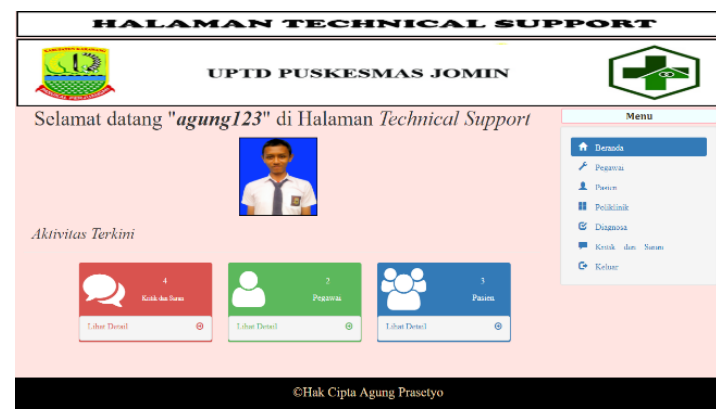

Gambar 16. Halaman Beranda Pegawai Technical Support 
Gambar 16, halaman Pegawai Technical Support ini berisikan aktivitas terkini mengenai jumlah kritik dan saran, jumlah pegawai, dan jumlah pasien lalu menu technical support yang berfungsi mengubah konten di halaman website.

\section{Spesifikasi Sistem Komputer}

1. Spesifikasi Perangkat Keras

Berdasarkan kondisi yang telah disebutkan diatas, maka dapat diusulkan untuk spesifikasi perangkat keras minimum untuk komputer yang akan digunakan:

a. Server

1) $\mathrm{CPU}$
a) Minimal
Processor
Intel $®$ Pentium ${ }^{\circledR}$ Core 2 Duo

b) Minimal RAM $100 \mathrm{MB}$

c) Minimal Hard Disk 1 GB

2) Mouse

3) Keyboard

4) Monitor dengan resolusi layar minimum $1024 \times 768$

b. Client
1) $\mathrm{CPU}$
a) Minimal Processor Intel ${ }^{\circledR}$ Pentium ${ }^{\circledR} 4$
b) Minimal RAM $20 \mathrm{MB}$
c) Minimal Hard Disk $317 \mathrm{MB}$
2) Mouse
3) Keyboard

2. Spesifikasi Perangkat Lunak

a. Server

1) Sistem operasi: Minimal Microsoft Windows 7

2) Aplikasi bundleweb server: Xampp yang terdiri dari beberapa komponen, diantaranya:
a) Aplikasi Apache Server v2
b) Aplikasi PHP Server v5
c) Aplikasi MySQL Server v5
d) Aplikasi phpMyAdmin v3

3) Aplikasi Web Browser seperti Mozilla Firefox, Opera, Safari, Internet Explorer, Google Chrome.

b. Client

1) Sistem operasi: Minimal Microsoft Windows XP
2) Aplikasi Web Browser seperti Mozilla Firefox, Opera, Safari, Internet Explorer, Google Chrome.

\section{Pengujian Unit}

Tabel 1.Hasil Pengujian Black Box

TestingHalaman Login Pegawai Administrasi

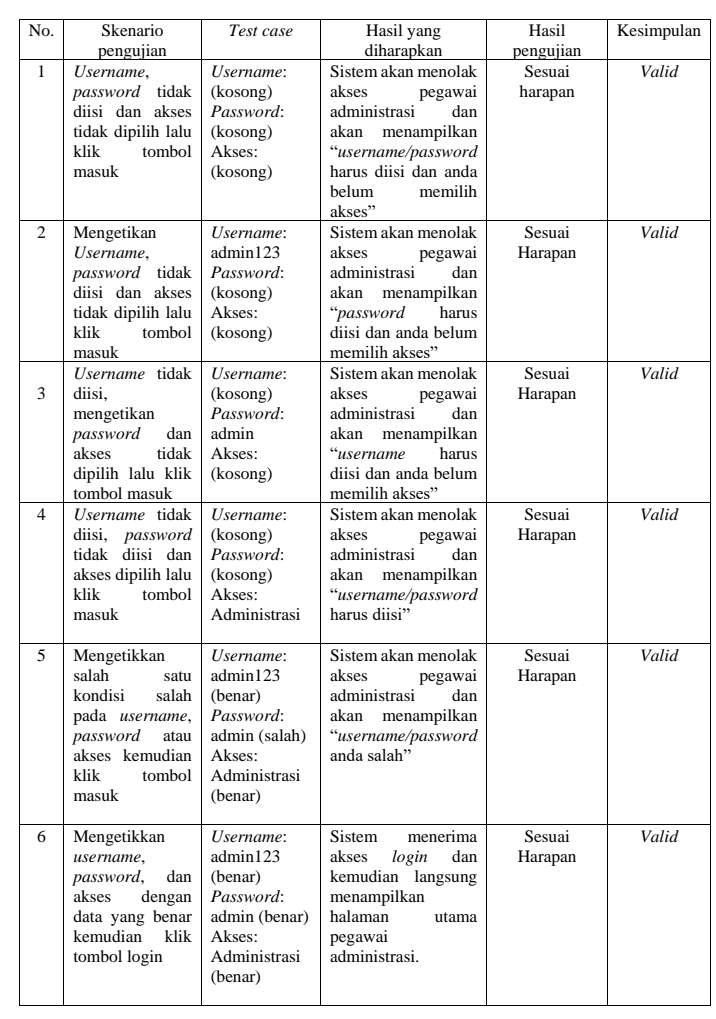

\section{KESIMPULAN DAN SARAN}

\section{Kesimpulan}

Dibuatnya website rekam medis ini, penulis dapat membuat beberapa kesimpulan diantaranya:

1. Pelayanan puskesmas berbasis web ini dapat memudahkan masyarakat dalam melakukan pendaftaran secara online, dan melakukan pemeriksaan secara mudah dan cepat.

2. Penggunaan sistem informasi ini dapat melakukan pengolahan data rekam medis yang dilakukan dengan penginputan data, mencetak data untuk dijadikan laporan, dimana semua data yang diperlukan 
disimpan dalam satu database.

3. Aplikasi website ini dapat mengatasi masalah penambahan data yang identik dengan kertas yang menumpuk dan memenuhi ruangan.

\section{Saran}

1. Sistem tidak hanya menangani rekam medis, sebaiknya dilengkapi dengan cara penangannnya, seperti memberikan rawat inap atau rawat jalan.

2. Perlu adanya evaluasi sistem secara berkala untuk mengimbangi perubahan-perubahan yang terjadi, sehingga masalah yang terjadi bisa teratasi.

3. Website ini sebaiknya dilakukannya perwatan secara berkala seperti back up file dan maintenance setiap sebulan sekali agar terhindar dari bug.

\section{DAFTAR PUSTAKA}

Davis, Gordon B. 2013. Kerangka Dasar Sistem Informasi Manajemen. Palembang: Maxikom.

Krismaji. 2015. Sistem Informasi Akuntansi. Yogyakarta: Unit Penerbit.

Mulyadi. 2016. Sistem Akuntansi. Jakarta: Salemba Empat.

Nilasari, Senja. 2014. Jago Membuat Website Gratis dan Cepat Secara Otodidak. Jakarta: Dunia Komputer.

Purnama, Benny dan Renny Afriani N. 2016. Analisis dan Perancangan Sistem Informasi Rekam Medis di Rumah Sakit TK. IV dr.Bratanata Jambi. Jurnal Manajemen Sistem Informasi Vol.1 No.2, Desember 2016 ISSN: 2540-8011.
Sommerville, Ian. 2011. Software Engineering (Rekayasa Perangkat Lunak). Jakarta: Erlangga. 